\title{
System Design of a Student Relationship Management System Using the Internet of Things to Collect the Digital Footprint
}

\author{
Nualsri Songsom, Prachyanun Nilsook, Panita Wannapiroon, Lance Chun Che Fung, and Kok Wai \\ Wong
}

\begin{abstract}
Information systems plays an important role in the development of many perspectives on the part of higher education institutions, especially in the management of students' lives. Systems must be accessible and meet the needs of students, and allow higher education institutions to receive accurate and appropriate information. The purpose of this research was to design a system in the form of a student relationship management system (SRMS) using the Internet of Things (IoT) to collect digital footprint. These include the provision of an overview service station for monitoring students the determination of relevant actors, the IoT process diagram, a sequence diagram and an entity relationship diagram. The results of the evaluation showed an overall very high level of appropriateness and a very high level in terms of the overall appropriateness of the usability of the system. All of the system design aspects for developing the system for collecting the digital footprint of higher education institutions to support student services and student behavior were shown to be appropriate.
\end{abstract}

Index Terms-System design, student relationship management system (SRMS), Internet of things (IoT), digital footprint.

\section{INTRODUCTION}

Higher education institutions currently engage in a high level of competition in terms of student services because students are central of higher education institutions. This means that students must be fully and thoroughly serviced [1].

Various information systems and technologies exist to support learning, competency, service and management for students [2]-[4] Innovative procedures with regard to student services must be made quickly accessible [5]. The Internet of Things (IoT) is a concept that connects people and devices which operates through the internet network which collects, monitors and manages data instantly [6]. The IoT is a technology that is popular and suitable for use with regard to tracking movements [2], [4]. Digital footprint are information that has been left behind in the Internet and can reflect who the user is and what are that person's interests. Therefore,

Manuscript received July 25, 2019; revised January 20, 2020.

Nualsri Songsom is with Suan Dusit University, Thailand (e-mail: nuasri_son@dusit.ac.th).

Prachyanun Nilsook and Panita Wannapiroon are with King Mongkut's University of Technology North Bangkok (KMUTNB), Thailand (e-mail: prachyanunn@kmutnb.ac.th, panitaw@kmutnb.ac.th)

Lance Chun Che Fung and Kok Wai Wong are with Murdoch University, Australia (e-mail: L.Fung@murdoch.edu.au, K.Wong@murdoch.edu.au). there has been a great deal of research involving the analysis of those data to ascertain the benefits in the way in which it can be used [7]-[9] Data tracking the movements of students using their digital footprint is an important and interesting issue. It is done using technology to track their movements and gathering the data to be processed, analyzed and summarized in order for it to be used by higher education institutions [2], [4], [7].

Songsom, Nilsook and Wannapiroon (2019) presented the conceptual framework of a SRMS using the IoT to collect digital footprint for higher education institutions. The design has three main parts: input, process and output. The first main part is input. This includes student relationship management, IoT and student affairs. The second main part of the process includes SRMS using the IoT, while the third main part is output which includes student services and student behavior as shown in Fig. 1 [10].

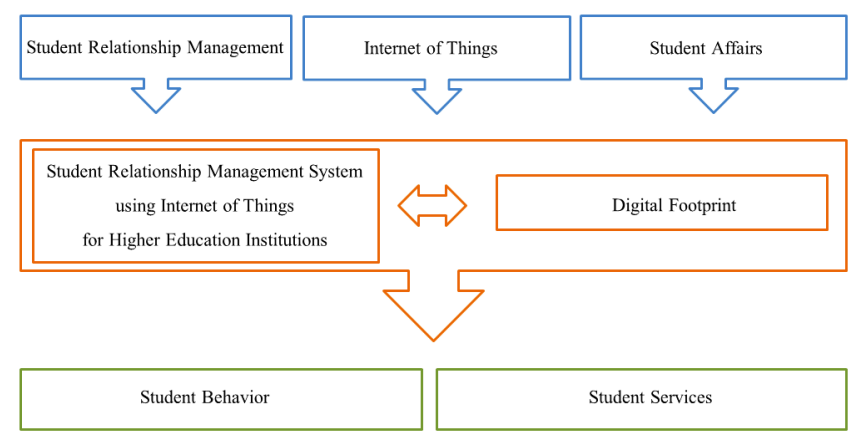

Fig. 1. The conceptual framework of an SRMS using the IoT to collect digital footprint for higher education institutions [10]

This research will offer a system design which uses the concept of IoT Technology to track student movements when entering the service station. The system will store digital footprint for processing and will issue reports to support the management of HEIs.

The background outlined and the significance of this research prompted the researchers to focus on the concept of system development, including the use of overview service stations, relevant actors, IoT process diagrams and sequence diagrams of an SRMS using the IoT to collect digital footprint.

\section{RESEARCH OBJECTIVES}

The research objectives of this study are as follows;

1) To design an overview service station for monitoring student of a SRMS using the IoT to collect the digital 
footprint

2) To design a SRMS using the IoT to collect the digital footprint

3) To evaluate the design of a SRMS using the IoT to collect the digital footprint

\section{RESEARCH MethodOlOGY}

The research into the design of a SRMS using the IoT to collect the digital footprint was conducted by reviewing documents, the literature and related research. The research was conducted in three phases as follows:

Phase I: Design of an overview service station for monitoring student of a SRMS using the IoT to collect the digital footprint.

Phase II: Design of a SRMS using the IoT to collect the digital footprint. The research instruments for this phase were: 1) relevant actors, 2) IoT process diagram, 3) sequence diagram, 4) Entity Relationship Diagram and 5) the evaluation metrics of the designed system.

Phase III: The evaluation of the SRMS using the IoT to collect the digital footprint by five experts who have experience in the field of system design, SRM, IoT and ICT using the purposive method.

\section{RESUlTS}

Phase I: Design of an overview service station for monitoring student of a SRMS using the IoT to collect the digital footprint.

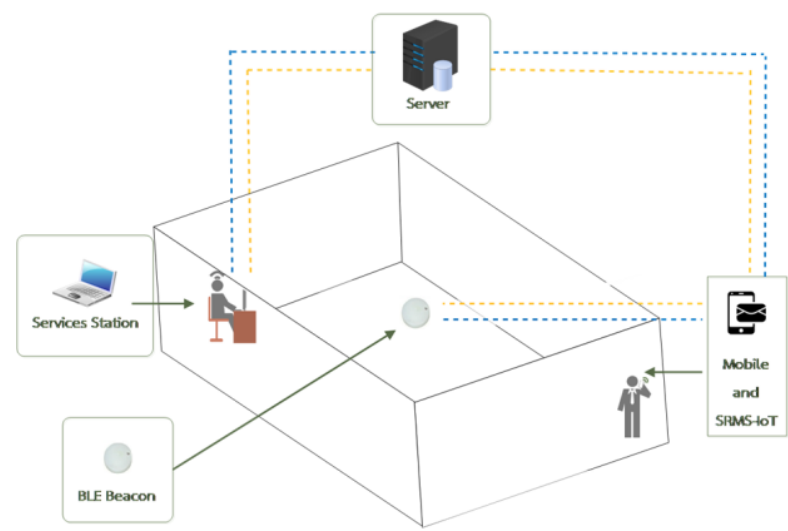

Fig. 2. Overview of the service stations for monitoring students of a SRMS using the IoT to collect the digital footprint.

The service station for monitoring students of a SRMS using the IoT to collect the digital footprint has four service stations which has providers at the service station. These are the library, academic services, student affairs and the first aid room. The students' mobile phones will install the SRMS-IoT system and when starting to use it will turn on the BLE signal. This will receive signals and transmit data systematically via the web server. An overview of the service stations of a SRMS using the IoT to collect the digital footprint is shown in Fig. 2. Each service station will set BLE Beacon as shown in Fig. 3,

Phase II: Design a SRMS using the IoT to collect the digital footprint. The research results for this phase related to: 1) Relevant Actors, 2) IoT Process Diagram, 3) Sequence
Diagram and 4) Entity Relationship Diagram.

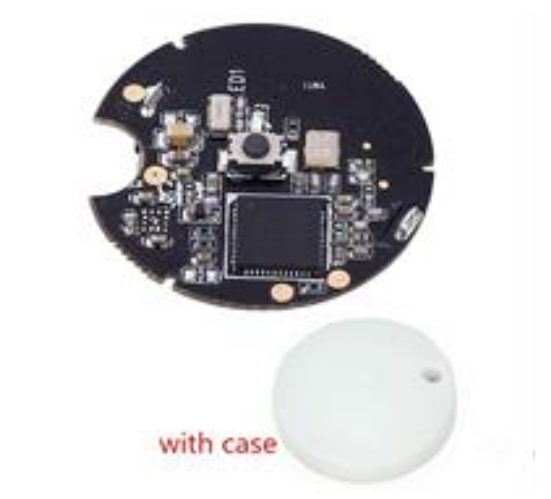

Fig. 3. BLE beacon [11].

\section{A. Relevant Actors}

A SRMS using the IoT to collect the digital footprint is used by five actors:

1) Students who access the service station and receive a service from the university.

2) Providers who manage the information service to students accessing each service station.

3) Teachers who monitor services and the behavior of students to manage classroom planning and teaching.

4) Managers who monitor the benefits of information from the system to use for the decision support system of the university.

5) Administrators who check, give advice, and maintain the system to ensure that it is effective.

\section{B. IoT Process Diagram}

The IoT Process Diagram illustrates the collaboration of the BLE Beacon and the SRMS-IoT. The SRMS-IoT has two main parts in the form of 1) Android Application and 2) Web Server.
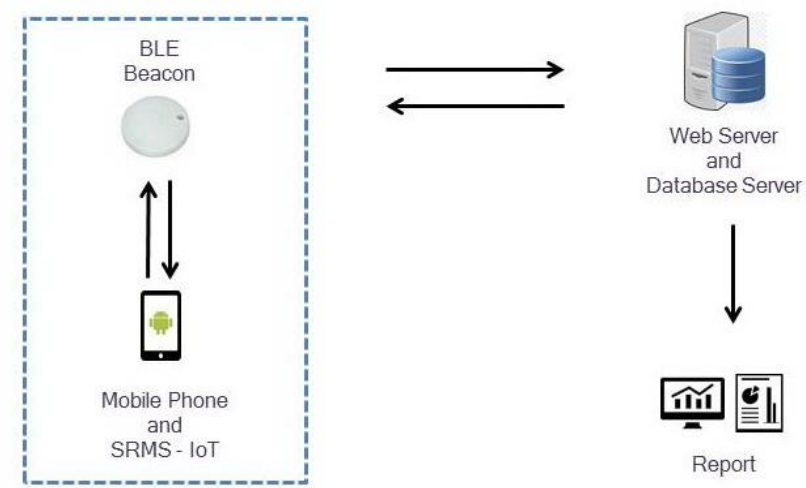

Fig. 4. The IoT process diagram of a SRMS using the IoT to collect the digital footprint.

The BLE Beacon is a device that identifies the location of the user by connecting the BLE Beacon to the Android Application. When a mobile phone installs SRMS-IoT and its users into the service station that has installed the BLE Beacon, the SRMS - IoT will receive a signal from the BLE Beacon, which in turn will send a signal to the Web Server. This will send information that identifies the User and the Service Station. When the Web Server receives the signal, it will send the data back to the Android Application in the form of an alert. The Web Server will store the access data 
with regard to the service station user, and process them for further reporting.

The IoT process diagram of a SRMS using the IoT to collect the digital footprint is shown in Fig. 4.

\section{Sequence Diagram}

The sequence diagram of a SRMS using the IoT to collect the digital footprint for a higher education institution is shown in Fig. 5.

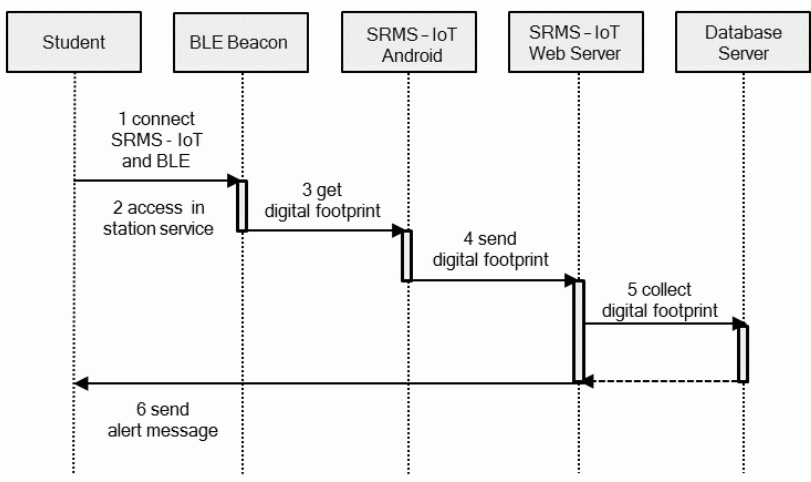

Fig. 5. Sequence diagram of a SRMS using the IoT to collect the digital footprint.

The above diagram depicts the sequence diagram of a SRMS using the IoT to collect the digital footprint

1) A SRMS - IoT and BLE signal is connected by the student.

2) Student accesses the service station where the BLE beacon is established.

3) BLE beacon gets a digital footprint including date, time, station_id and student_id to the SRMS - IoT Android.

4) SRMS - IoT Android sends the digital footprint to the SRMS - IoT Web Server.

5) SRMS - IoT Web Server collects the digital footprint in the Database Server.

6) Finally, the SRMS - IoT Web Server sends an alert message to the student.

\section{Entity Relationship Diagram}

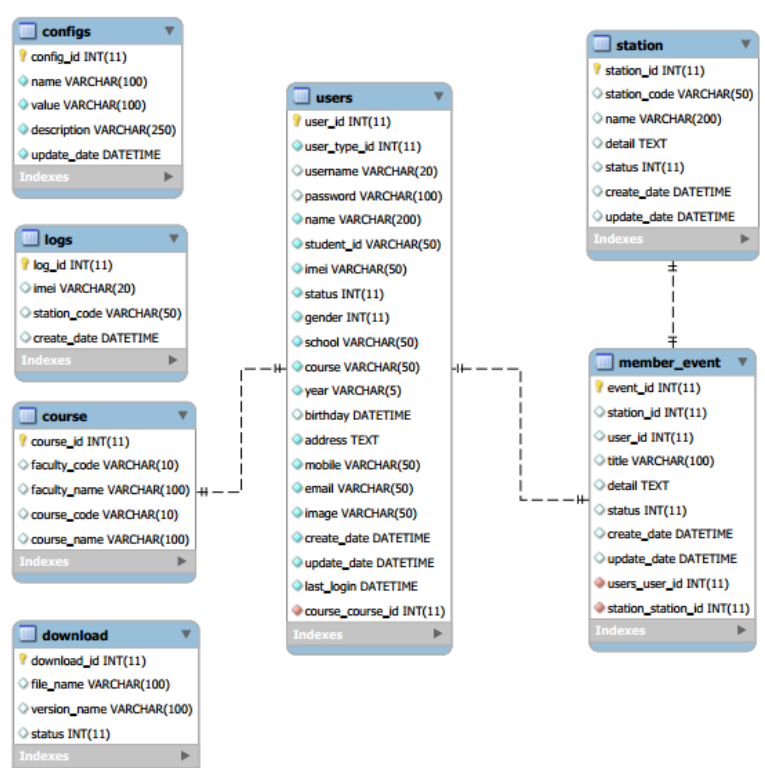

Fig. 6. Entity relationship diagram of a SRMS using the IoT to collect the digital footprint.
The Entity Relationship diagram of a SRMS using the IoT to collect the digital footprint is shown in Fig. 6.

The table containing the ER Diagram has three parts:

Part 1: Table user that stores the history of students by linking to table course.

Part 2: Table station stores the service station where the BLE Beacon is set, and links it to the table member event member event which collects data about student access and leave of service stations.

Part 3: Other tables related to systems management and data processing include table log, table config and table download.

Phase III: Evaluation of the design of a SRMS using the IoT to collect the digital footprint is shown in Table I and Table II.

TABLE I: EVALUATION OF THE SYSTEM DESIGN OF A SRMS USING THE IOT TO COLLECT THE DIGITAL FOOTPRINT

\begin{tabular}{lccc}
\hline \hline \multicolumn{1}{c}{ List of Evaluation } & $\overline{\boldsymbol{x}}$ & S.D. & Level of \\
& & & appropriateness \\
\hline 1. Relevant Actors & 4.60 & 0.55 & very high \\
2. IoT Process Diagram & 4.60 & 0.55 & very high \\
3. Sequence Diagram & 5.00 & 0.00 & very high \\
4. Entity Relationship Diagram & 4.20 & 0.45 & high \\
\hline Total & $\mathbf{4 . 6 0}$ & $\mathbf{0 . 2 6}$ & very high \\
\hline \hline
\end{tabular}

According to Table I, the overall results of the evaluation of the design of a SRMS using the IoT to collect the digital footprint was at a very high level of appropriateness $(\bar{x}=$ 4.60, S.D. $=0.26)$. Considering each item, most items were at a very high level of appropriateness, with the exception of the entity relationship diagram, which was at a highly appropriate level.

TABLE II: EVALUATION OF THE USABILITY OF THE DESIGN OF A SRMS USING THE IOT TO COLLECT THE DIGITAL FOOTPRINT

\section{Level of}

List of Evaluation $\quad \bar{x} \quad$ S.D.

appropriateness

1. The design suitability of

$\begin{array}{lll}5.00 & 0.00 \quad \text { very high }\end{array}$

overview service station

2. The suitability of the IoT

(BLE beacon) in terms of $5.00 \quad 0.00$ very high

supporting the system

$\begin{aligned} & \text { 3. The suitability for } \\
& \text { implementation }\end{aligned}$
\begin{tabular}{rlcc} 
Total & 4.60 & 0.55 & very high \\
\hline 4.87 & $\mathbf{0 . 3 2}$ & very high
\end{tabular}

According to Table II, the overall result of the evaluation 
of the usability of the system design of a SRMS using the IoT to collect the digital footprint was at a very high level of appropriateness $(\bar{x}=4.87$, S.D. $=0.32)$. Considering each item, most items were at a very high level of appropriateness.

\section{DiSCUSSION AND CONCLUSION}

According to the results of our evaluation of the design of a SRMS using the IoT to collect the digital footprint, the level of overall appropriateness was at a very high level, with the exception of the entity relationship diagram, which indicated a high level of appropriateness. The overall appropriateness of the usability result was at a very high level, which showed that the experts had consistent opinions.

As shown in the design of a SRMS using the IoT to collect the digital footprint, we have included relevant actors, the IoT process diagram, a sequence diagram and an entity relationship diagram. This is in accordance with Kuandee, Nilsook and Wannapiroon [12] who designed and developed an asset supply chain management system-based on IoT technology for Higher Education Institutions (HEIs). This result in terms of system analysis and design consisted of: 1) stakeholders, 2) the IoT process diagram 3) a sequence diagram designed for monitoring assets and accordance with Premsmith, Wannapiroon and Nilsook [13] who designed the challenge-based learning management system. The result in term of system analysis and design consisted of: 1) use case 2) sitemap 3) sequence diagram and 4) entity relationship diagram.

\section{CONFLICT OF INTEREST}

The authors declare no conflict of interest.

\section{AUTHOR CONTRIBUTIONS}

Nualsri Songsom studied literature review, designed system and wrote paper. Prachyanun Nilsook and Panita Wannapiroon created the evaluation form, collected and analyzed the data. Lance Chun Che Fung and Kok Wai Wong advised and had approved the final version.

\section{ACKNOWLEDGMENT}

This work is partly supported by Suan Dusit University (SDU), Thailand, King Mongkut's University of Technology North Bangkok (KMUTNB), Thailand and Murdoch University, Perth, Western Australia.

\section{REFERENCES}

[1] K. Roger and H. E. Danja, "Student affairs and services in higher education: Global foundations, issues and best practices," In Cooperation with: The United Nations Educational, Scientific and Cultural Organisation (UNESCO), International Association of Student Affairs and Services (IASAS), 2009.

[2] H. D. Rjeib, N. S. Ali, A. A. Farawn, and B. Al-Sadawi, "Attendance and information system using RFID and web-based application for academic sector," (IJACSA) International Journal of Advanced Computer Science and Applications, vol. 9, no. 1, pp. 266-274, 2018.

[3] T. Namnual, P. Nilsook, and P.Wannapiroon, "System architecture of data warehousing with ontologies to enhance digital entrepreneurs competencies for higher education," International Journal of Information and Education Technology, vol. 9, no. 6, pp. 414-418, 2019.
[4] H. Alqahtani and H. Al-Sakran, "Towards safe commuting: Using internet of things for building smart student tracking system," International Journal of Advanced Research in Computer Science and Software Engineering, vol. 6, no. 11, pp. 32-42, November 2016.

[5] D. J. Burnett, Innovation in Student Services: Best Practice and Process Innovation Models and Trends, 2010.

[6] T. Zhang, "The internet of things promoting higher education revolution," presented at 2012 Fourth International Conference on Multimedia Information Networking and Security, 2014.

[7] J. Hinds and A. M. Joinson, "What demographic attributes do our digital footprints reveal? A systematic review," PLOS ONE, vol. 13, no. 11, p. e0207112, 2018.

[8] S. Fan, P. Li, T. Liu, and Y. Chen, "Population behavior analysis of chinese university students via digital campus cards," in Proc. IEEE 15th International Conference on Data Mining Workshop, pp. 72-77, 2015 .

[9] A. Malhotra, L. Totti, W. Meira, P. Kumaraguru, and V. Almeida, "Studying user footprints in different online social networks," presented at IEEE/ACM International Conference on Advances in Social Networks Analysis and Mining, 2013.

[10] N. Songsom, P. Nilsook, and P. Wannapiroon, "The synthesis of the student relationship management system using the internet of things to collect the digital footprint for higher education institutions," International Journal of Online and Biomedical Engineering (iJOE), vol. 15, no. 6, pp. 99-112, 2019.

[11] Ibeacon Base Station Intelligent Control System. [Online]. Available: https://www.solidrop.net/product/5pcs-nrf51822-2v-3-3v-bluetooth-4wireless-module-for-ibeacon-base-station-intelligent-control-system-b eacon-ble-4ma-w-case.html

[12] W. Kuandee, P. Nilsook, and P. Wannapiroon, Asset supply chain management system-based IoT technology for higher education institutions," International Journal of Online and Biomedical Engineering (iJOE), vol. 15, no. 3, pp. 4-20, 2019.

[13] J. Premsmith, P. Wannapiroon, and P. Nilsook, "System design of challenge-based learning management system," in Proc. the 4th International Conference on Technical Education, 2016, November 24, pp. 27-33.

Copyright (C 2020 by the authors. This is an open access article distributed under the Creative Commons Attribution License which permits unrestricted use, distribution, and reproduction in any medium, provided the original work is properly cited (CC BY 4.0).

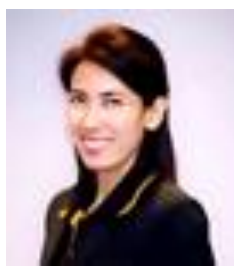

Nualsri Songsom is a lecturer of business computer, Faculty of Management, Suan Dusit University, Thailand. Her research interests focus on student relationship management, internet of things, and digital footprint.

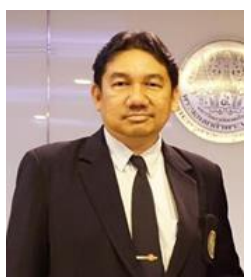

Prachyanun Nilsook is an associate professor at the Division of Information and Communication Technology for Education, King Mongkut's University of Technology North Bangkok (KMUTNB), Thailand. He currently works in the field of ICT for Education and Vocational Education Technology Research Centre. He is a member of Professional Societies in the Association for Educational Technology of Thailand (AETT).

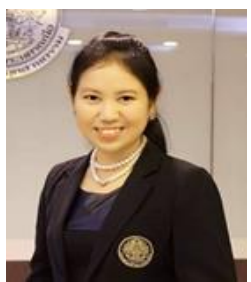

Panita Wannapiroon is an associate professor at the Division of Information and Communication Technology for Education, and the Director of Innovation and Technology Management Research Centre (ITMRC), Science and Technology Research Institute (STRI), King Mongkut's University of Technology North Bangkok (KMUTNB), Thailand. Presently, she works in the field of ICT in Education. 


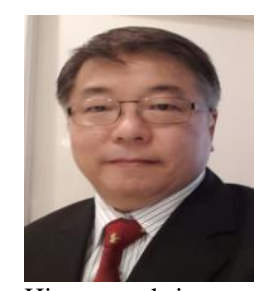

Lance Chun Che Fung is an emeritus professor in the College of Science, Health, Engineering and Education at Murdoch University in Western Australia. He is also the current chapter chair IEEE New Initiatives Committee (NIC), chair for IEEE Asia Pacific Region Educational Activities Committee (R10 EAC) and chair for IEEE Systems, Man and Cybernetic (SMC) Society (WA Chapter) His research interest is in the development and applications of innovative intelligent

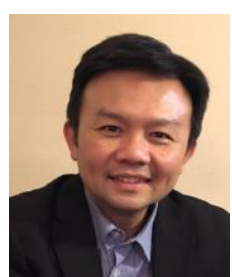

Kok Wai Wong is an associate professor with the discipline of information technology, mathematics and statistics at the College of Science, Health, Engineering and Education at Murdoch University in Western Australia. He is the current vice president (Membership) for The Asia Pacific Neural Network Society (APNNS). He is a senior member of Institute of Electrical and Electronics Engineers (IEEE), a senior member of Australia Computer Society (ACS), and Certified Professional of ACS. He is also the current chapter chair for IEEE Computer Intelligence Society (WA Chapter). He is involved in the editorial boards for a number of international journals and in many international conference organising committees. His current research interests include intelligent data mining, artificial intelligence and machine learning, and game and virtual reality technology. 